\title{
Internet e Parlamento \\ Um estudo dos mecanismos \\ de participação oferecidos pelo Poder \\ Legislativo através de ferramentas online ${ }^{1}$
}

\author{
Francisco Paulo Jamil Almeida Marques² \\ UFBA \\ marquesjamil@yahoo.com.br \\ Edna Miola 3 \\ UFBA \\ ednamiola@yahoo.com.br
}

\begin{abstract}
Resumo: O trabalho examina as ferramentas de participação oferecidas aos cidadãos através dos websites de seis casas legislativas brasileiras: a Câmara dos Deputados e as Assembléias de cinco estados (Bahia, Goiás, Pará, Rio Grande do Sul e São Paulo). Para se considerar a adequação dos recursos participativos disponíveis em tais websites, empregou-se a perspectiva deliberacionista de democracia. Dentre os principais resultados da investigação, aponta-se que, à exceção do site da Câmara, as iniciativas em questão ofertam recursos limitados de participação, o que sugere um subaproveitamento do potencial técnico dos media digitais.
\end{abstract}

Palavras-Chave: Internet - Deliberação - Participação

\footnotetext{
${ }^{1}$ Uma versão preliminar deste trabalho foi apresentada na IV Jornadas de Comunicação e Democracia entre os grupos de pesquisa da UFBa e UFMG, em Belo Horizonte, maio de 2007. Os autores são gratos às observações tecidas pelos colegas quando da realização deste encontro

2 Aluno do Doutorado do Programa de Pós-Graduação em Comunicação e Cultura Contemporâneas da UFBa. Bolsista do CNPq.

3 Aluna do Mestrado do Programa de Pós-Graduação em Comunicação e Cultura Contemporâneas da UFBa. Bolsista do CNPq.
} 
Abstract: This article examines the opportunities of participation offered by six Brazilian Parliament websites: the Federal House of Representatives, and its corresponding Assemblies in five states (Bahia, Goiás, Pará, Rio Grande do Sul, and São Paulo). In order to consider how adequate the participatory resources found in these websites are, one takes into account the deliberative model of democracy. All the experiences but the Federal House of Representatives' website are shy regarding the employment of the tools technically available.

Keywords: Internet - Deliberation - Participation

Résumé : Cet article examine les opportunités de participation offertes aux citoyens par six sites parlementaires brésiliens : la Chambre des Députés et les Assemblées de cinq états (Bahia, Goiás, Pará, Rio Grande do Sul et São Paulo). Afin de considérer l'adéquation des ressources participatives disponibles dans tels websites, on fait usage du modèle délibératif de démocratie. Parmi les résultats de la recherche, on indique que, à l'exception $d u$ site de la Chambre des Députés, les initiatives étudiés offrent des ressources limitées de participation si on considére le potentiel technique des médias digitaux.

Mots-clé : Internet - Délibération - Participation.

\section{Introdução}

Uma maior apreensão social dos recursos digitais vem mostrando, com o passar do tempo, que, em vez de uma cultura ou de uma vida digital (NEGROPONTE, 1995), ou de um discurso que defenda apenas os benefícios, os malefícios ou as neutralidades das ferramentas, parece haver maior confiabilidade em uma interpretação afeita aos fenômenos sociais permeados (mas não definidos) pelas tecnologias de comunicação. Ou seja, as investigações correntes de maior proeminência em várias áreas de estudo procuram se abrigar daqueles extremismos encontrados nas fases iniciais de pesquisas relativas aos new media, como determinismos sociais ou tecnológicos. 
Mais particularmente no que se refere ao emprego das ferramentas digitais para o aperfeiçoamento das democracias, objeto de interesse do presente trabalho, uma opção consiste em estudar em que medida efetivamente se dá este processo de adoção das ferramentas por parte de instituições do Estado. Este artigo busca, assim, diagnosticar que tipos de instrumentos e recursos são efetivamente oferecidos por determinada categoria de websites e de agentes políticos no que se refere ao provimento de mecanismos de participação política a serem empregados pela esfera civil.

As experiências escolhidas para este trabalho se referem a um conjunto de instituições do Poder Legislativo. Os Legislativos federal e estaduais são espaços por excelência nos quais, idealmente, do ponto de vista de uma democracia forte, a soberania popular deveria ser exercida com maior vigor. Rousseau (2002), por exemplo, considerava que a capacidade de formular as leis não poderia, sequer, ser delegada a representantes, pois a um povo só se atribui liberdade real na medida em que ele tem a capacidade de elaborar e modificar, de modo autônomo, as normas que regem o contrato social. Por outro lado, o próprio Rousseau considerava os limites de determinados ideais seus e não chegou a vislumbrar como viável a configuração de um Poder Legislativo exercido diretamente pela esfera civil em sociedades que reunissem mais do que alguns milhares de cidadãos. $\mathrm{O}$ artifício da representação, assim, desde o advento dos Estados-Nação, tem uma parcela importante de contribuição para que o regime democrático de governo permaneça factível. A manutenção da representação, porém, não significa ser legítimo o prevalecimento de uma separação rígida entre esfera civil e esfera política quando do processo de produção da decisão política (GOMES, 2005).

Neste contexto, para examinar se e em que medida os recursos oferecidos pela Internet vêm sendo empregados por instituições do Legislativo no sentido de fomentar um novo tipo de relação entre esfera civil e esfera política, o trabalho se sustenta em dois tópicos centrais. Na próxima parte, são discutidas as naturezas dos diferentes tipos de oportunidades de participação política que deveriam, idealmente, ser oferecidos por instituições do Poder Legislativo através da Internet. Na intenção de se caracterizar e definir as ferramentas digitais consideradas adequadas para se promover a participação da esfera civil, recorre-se a uma perspectiva deliberacionista 
de democracia. Ou seja, dada a essência de discussão e elaboração das leis nas casas congressuais, considera-se que os princípios deliberativos de democracia deveriam, de algum modo, exercer influência quando da configuração dos recursos ofertados através das redes digitais de comunicação.

Em seguida, o trabalho põe luz sobre determinadas experiências de instituições legislativas no intuito de identificar e analisar as modalidades de participação oferecidas aos cidadãos mediante recursos da Internet. São destacados para ilustrar o argumento aqui delineado os sites das Assembléias Legislativas de cinco estados (Bahia, Goiás, Pará, Rio Grande do Sul e São Paulo) e o site da Câmara dos Deputados.

\section{Poder Legislativo e oportunidades de participação política: a perspectiva deliberacionista como fundamento teórico}

Não parece plausível examinar se a Internet pode ser considerada um ambiente de comunicação apto a aperfeiçoar as práticas democráticas se não se apela para uma fundamentação teórica que contemple um reconhecimento mínimo de determinados pressupostos dos modelos de democracia. Ou seja, pergunta-se até que ponto se pode afirmar consistentemente que um website ou uma dada ferramenta preenche os requisitos de uma participação política adequada dos cidadãos se não se esclarece o que se entende por participação e nem o seu alcance. Nestes termos, é necessário delinear, preliminarmente, a concepção adotada de democracia e as conseqüências que tal compreensão traz para a avaliação dos mecanismos digitais.

O referencial de modelo democrático aqui empregado para se avaliar os dispositivos oferecidos por websites legislativos se fundamenta na perspectiva deliberacionista, cujos pressupostos consideram uma depreciação do ideal de soberania popular a separação rígida entre o trabalho político dos representantes eleitos e o da esfera civil.

Assim, ao contrário do modelo liberal, a vertente deliberativa considera que a participação deve ir além do simples ato de votar ou do acompanhamento cotidiano das práticas políticas através dos mass media. Ou seja, mesmo levando em conta o voto e a atualização dos fatos políticos a partir da esfera privada como aspectos pertinentes às sociedades democráticas, autores a exemplo de John Dryzek (2004), 
John Gastil (2000) e James Fishkin (1991) insistem que estas formas de contato entre o cidadão e o campo político são limitadas, pois se encontram presas a uma visão de mundo particularista. Percebe-se, aqui, uma rejeição ao ideal de modelos como o elitismo de Schumpeter (1942) e a teoria econômica da democracia de Downs (1999), cujos pressupostos dão conta de que os cidadãos agem de modo individualista e sem se preocuparem com o bem comum.

Isto significa que, de acordo com o modelo deliberativo, os cidadãos devem ter oportunidades de interferência efetiva quando da produção da decisão política, sendo que as instituições da democracia devem atuar de maneira favorável a uma aproximação entre cidadãos e representantes. James Bohman identifica, assim, a importância da inclusão dos cidadãos na discussão pública que ocorre no âmbito das instituições políticas do Estado democrático:

... the sovereignty of deliberative majorities in complex societies requires a complex series of interchanges between public and political institutions of all kinds. [...] The problem is that the mechanisms of this interchange with the public are not adequate for ensuring deliberation, even in legislative institutions. [...] Indeed, the interchange between public and bureaucratic and administrative institutions constitutes the biggest challenge for public deliberation (BOHMAN, 1996, p. 187-188).

O deliberacionismo, nestes termos, considera que uma participação adequada se torna viável graças à consecução de três fatores: primeiro, a busca por arranjos institucionais adequados para receberem as disposições e para processarem as razões da esfera civil erigidas em público; segundo, devem ser promovidas circunstâncias sociais favoráveis para que os cidadãos tenham condições mínimas de intervir no diálogo que caracteriza uma deliberação genuinamente pública; terceiro, uma vez que as condições externas (disponibilidade de mecanismos e um quadro sócio-econômico favorável) estejam contempladas, a participação dos cidadãos deve ser internamente orientada de modo a satisfazer determinados princípios deliberativos, a saber, aqueles de reciprocidade, publicidade e accountability propostos, com maior ênfase, por Gutmann e Thompson (1996).

Na estrutura deliberativa, a participação dos cidadãos, aliada à busca por razões de natureza pública, é o que possibilita uma decisão ser considerada legítima. Isto é, o ideal deliberacionista delineia um tipo adequado de intromissão dos 
cidadãos na formulação da decisão política a partir de uma troca pública de razões que tenha em vista os princípios de reciprocidade, publicidade e accountability.

Por reciprocidade, Gutmann e Thompson compreendem a necessidade de que os agentes que tomam parte na deliberação pública (1) reconheçam e considerem respeitosamente os indivíduos envolvidos no processo discursivo, bem como as razões por eles erigidas e (2) apresentem razões que sejam mutuamente aceitáveis pelos pares. O requisito da publicidade afirma que, para serem exitosas quanto à obtenção do consentimento da sociedade, as razões e justificativas empregadas, bem como as informações necessárias para avaliá-las, devem ser de conhecimento público ou estar publicamente acessíveis. Já o princípio da accountability pode ser traduzido como "prestação de contas" ou "responsabilização". Este requerimento afirma a necessidade (1) dos representantes exporem aos cidadãos os motivos para se adotar determinada política e de (2) se mostrarem abertos e "responsíveis" aos questionamentos eventualmente tecidos (Gutmann e Thompson, 1996).

Compreende-se que, internamente, as casas legislativas estão formatadas de modo a atuar de acordo com parâmetros deliberativos. Ou seja, pelo menos do ponto de vista formal, o processo de produção da decisão política nas casas legislativas pode ser considerado deliberativo, já que os mecanismos de input institucionais são garantidos a todos os parlamentares. Em segundo lugar, nenhum dos parlamentares tem suas razões excluídas do debate por carência de condições sócio-econômicas. E, terceiro, ao longo do processo de discussão, há espaço para se fomentar a cooperação e uma troca legítima de razões graças à, dentre outros fatores, existência de um código parlamentar de conduta moral.

Se, para os representantes eleitos, a deliberação é formalmente concebível, o desafio proposto pelo modelo de democracia aqui adotado se refere à expansão da discussão pública relativa ao processo de produção da decisão política. O deliberacionismo não chega a defender que todos os cidadãos tomem parte na íntegra dos debates. O que tal vertente requer é que aos cidadãos sejam dadas as oportunidades de influir e de terem considerados seus motivos e reivindicações à luz da razão pública. Em suma, a criação de mecanismos institucionais porosos o suficiente para absorver as razões e as demandas dos cidadãos, aliada à efetividade institucional que deve ser transmitida aos integrantes da esfera civil para que estes se 
sintam estimulados a atuar politicamente, são as marcas a idealmente caracterizarem a configuração dos recursos disponíveis através dos websites legislativos.

\section{Das características das ferramentas deliberativas}

A partir destas considerações, pergunta-se quais das ferramentas de participação oferecidas por websites do Poder Legislativo são aptas a preencherem os requisitos do modelo deliberacionista. Certamente, devem ser considerados aqueles mecanismos que pressupõem alguma forma de input por parte dos cidadãos, ou seja, artifícios que solicitam contribuições dos usuários através, preferencialmente, da troca de argumentos.

Ressalte-se que pode haver diferentes tipos de input oferecidos aos cidadãos através dos websites. Cite-se o caso das sondagens simples de opinião pública. As sondagens são exemplos de ferramentas que possibilitam a participação de um número considerável de cidadãos mas sem, ao mesmo tempo, significar o advento de um recurso deliberativo. Questiona-se até que ponto os registros das disposições dos cidadãos neste tipo de pesquisa podem ser considerados recursos deliberativos se não estimulam, por exemplo, a troca de razões. Em outras palavras, tomando-se como fundamento para a avaliação dos dispositivos o modelo deliberativo de democracia, é necessário que se procure pensar em recursos que registrem não apenas a disposição dos cidadãos, mas que impliquem reflexões que se incorporam em um processo de contínua elaboração e aperfeiçoamento das razões e das decisões.

Ao assumir como adequada uma natureza específica de ferramentas de participação, que outros tipos de mecanismos deveria, então, um website de instituição legislativa tornar disponível? Provavelmente, uma das respostas poderia se referir à presença de formulários eletrônicos nos quais o usuário sugere, tira dúvidas ou mesmo faz denúncias. Por mais que esta seja uma ferramenta de maior qualidade do ponto de vista deliberativo do que a simples sondagem de opinião, já que há uma troca de argumentos e a possibilidade de interlocução, deve-se levar em conta que o patamar estabelecido pelo deliberacionismo procura privilegiar uma perspectiva de participação pública, ou seja, os autores deliberativos demonstram preferência por um processo que inclua diversos agentes dispostos em arena pública para o confronto de argumentos, e não apenas uma participação individual 
(BOHMAN, 1996). É a partir destas constrições e requerimentos que se vai formatando a idéia do que seria considerado adequado como ferramenta de participação de tipo deliberativo.

Dos recursos de input que não necessariamente mobilizam o emprego de razões públicas, mas, nem por isso, são descartáveis, pode ser listado aquele referente à "seção de cartas" (disponível no site do Senado chileno4), na qual os cidadãos podem expor suas opiniões em comentários publicados no website. Este tipo de iniciativa é semelhante ao que o modelo deliberativo reconhece como testemunho. A importância do testemunho na deliberação pública se encontra no fato de que, não obstante as desigualdades de condições sócio-econômicas ou mesmo nas capacidades em elaborar argumentos convincentes, qualquer cidadão teria a oportunidade de oferecer seu ponto-de-vista a partir da narração de experiências de vida. Por outro lado, conforme afirmam Gutmann e Thompson, os testemunhos não preenchem, na maioria dos casos, os requerimentos de princípios deliberativos, a exemplo da publicidade (1996, p. 136-137).

Uma outra forma de input oferecida aos cidadãos pelos legislativos, e empregada nos países europeus mesmo antes do advento dos media digitais, são as petições. O envio individual ou coletivo de petições é um dispositivo previsto nas legislações internas de países como Escócia ${ }^{5}$ e Portugal $^{6}$ e se constitui norma, ainda, da União Européia7. Conforme relatório da OECD, as petições são um importante instrumento para que o público inclua determinadas questões na pauta de discussão do poder legislativo (OECD, 2003, p. 56).

Os websites de tais casas legislativas européias facilitam o emprego deste recurso ao oferecer informações acerca de como formular uma petição. Os parlamentos de Portugal, Escócia e o europeu ofertam, ainda, a possibilidade de se preencher e enviar petições online. No caso de Portugal e Escócia, uma vez submetidas as petições, o responsável pela reivindicação pode acompanhar o processamento das demandas já encaminhadas. Os três sites acima citados tornam disponível, também, endereço de e-mail para esclarecimentos adicionais. Uma outra

4 Disponível em: <http://www.senado.cl $>$. Acesso em 14/05/2007.

5 Disponível em: $<$ http://www.scottish.parliament.uk $>$. Acesso em 14/05/2007.

${ }^{6}$ Disponível em: <http://www.assembleia.pt $>$. Acesso em 14/05/2007.

7 Disponível em: <http://www.europarl.europa.eu/>. Acesso em 14/05/2007. 
peculiaridade identificada no site do parlamento escocês se refere à capacidade conferida aos usuários em, além de acessar o conteúdo das petições já enviadas, poder avaliá-las e publicar, no próprio website, suas impressões e comentários. Ressalte-se que, igualmente aos testemunhos, as petições não apresentam restrições quanto ao assunto ou às razões que fundamentam as demandas encaminhadas e nem promovem, necessariamente, uma participação deliberativa.

Por outro lado, as petições diferem dos testemunhos, pois estes não requerem que o cidadão elabore argumentos à luz da razão pública, mas que, na verdade, exponha sua vivência, enquanto que, nas próprias instruções para preenchimento das petições, os interessados são orientados a justificarem suas demandas sob pena destas serem excluídas do processo de análise.

Dentre os dispositivos que permitem a publicação das opiniões dos cidadãos, encontra-se a experiência do Chile, que, embora não disponha de um fórum virtual, oferece a oportunidade de opinar de forma aprofundada, através de sondagens detalhadas sobre matérias em discussão no plenário. Estão disponíveis, como dispositivos a facilitar o acesso de informações, referências bibliográficas, consultas à atual legislação chilena e de outros países acerca daquela questão. Neste caso, mais do que o registro relativo à escolha entre sim e não, o cidadão é convidado a refletir sobre os conteúdos essenciais da proposta e se posicionar em relação e eles, podendo, ainda, adicionar suas próprias questões de modo descritivo, em formulário eletrônico. As opiniões de outros cidadãos estão disponíveis para consulta, assim como os comentários a elas adicionados.

Considerando-se as ferramentas adequadas do ponto de vista deliberativo para a participação, pode-se citar a possibilidade dos cidadãos participarem de conversas online (através das chamadas "salas de bate-papo") com especialistas em determinadas matérias e/ou com legisladores. Dentre as vantagens deste dispositivo, está a possibilidade dos cidadãos formarem um juízo em conjunto com especialistas e parlamentares. Deve ser ressaltada, assim, a capacidade dos cidadãos em emitir juízos e em contribuir efetivamente no debate ao colocarem suas próprias perspectivas e visões de mundo. Mesmo que tal processo de debate não gere uma decisão ao final da discussão (isso porque o poder decisório continua nas mãos dos eleitos, já que o modelo deliberativo não defende o fim da representatividade), tanto 
cidadãos quanto parlamentares poderiam sair da deliberação pública com visões diferentes acerca do seu posicionamento inicial.

Uma modalidade de ferramenta semelhante ao bate-papo, por conformar situações de discussão deliberativa com a capacidade de arregimentar públicos maiores, são os fóruns. Tais ambientes proporcionam uma discussão potencialmente mais qualificada e plural, já que, devido ao maior tempo e espaço disponíveis para a elaboração dos argumentos, os discursos podem ser mais consistentes do que na dinâmica de perguntas e respostas instantâneas característica dos bate-papos. O website da Assembléia da República de Portugal dispõe de um fórum de discussão aberto aos cidadãos, sem requerer registro prévio do participante.

Pôde-se perceber uma escala qualitativa no que se refere ao perfil dos recursos disponíveis à interferência civil em websites do Poder Legislativo. Desde as simples sondagens de opinião (nas quais há uma forma de participação individualizada e sem troca de argumentos públicos) até a oferta de fóruns (onde um maior número de cidadãos pode tomar parte nos debates, o que implica um giveand-take de idéias), o que se procurou fazer neste tópico foi um apanhado das características ideais daqueles mecanismos considerados adequados à participação do ponto-de-vista deliberativo e tecnicamente viáveis.

O perfil de uma ferramenta deliberativa que favorece a participação pode ser delineado a partir das seguintes características: o recurso deve permitir a troca de razões entre diversos agentes, auferindo-se a todos os participantes oportunidades de inserir, questionar e justificar posicionamentos. Idealmente, o resultado de deliberações públicas desta natureza deve servir de subsídio e, conseqüentemente, influenciar as decisões parlamentares. No próximo tópico, são examinadas seis experiências brasileiras de sites legislativos.

\section{Poder Legislativo e oportunidades de participação política: experiências brasileiras}

O trabalho examina as ferramentas participativas oferecidas por websites de seis legislativos brasileiros: a Câmara dos Deputados ${ }^{8}$ e as Assembléias dos cinco

\footnotetext{
${ }^{8}$ Disponível em: <http://www2.camara.gov.br/>. Acesso em 14/05/2007. 
maiores estados de cada região em termos populacionais, Bahia9 ${ }^{9}$ Goiás ${ }^{10}$, Paráa ${ }^{11}$, Rio Grande do $\mathrm{Sul}^{12}$ e São Paulo ${ }^{13}$. Conforme já enfatizado, o estudo desenvolvido pretendeu analisar as diferentes formas de input oferecidas aos cidadãos através destes websites, tomando como ponto de referência para avaliar a adequação destes mecanismos a perspectiva deliberacionista de democracia.

Os seis sites possuem uma estrutura mínima de design que contempla informações sobre o parlamento, seu histórico, estrutura organizacional e que, em alguns casos, versa sobre o funcionamento das rotinas legislativas; nota-se, ainda, a presença de seções dedicadas a prover dados sobre os deputados, as comissões e as legislações em voga.

Pode-se notar que o site da Câmara dos Deputados é aquele que oferece os melhores recursos de participação aos cidadãos. Apesar da maioria dos mecanismos encontrados neste e nos outros casos da amostra privilegiar o fornecimento de informações, o website da Câmara é peculiar por nele serem verificáveis experiências interessantes de efetiva participação deliberativa.

Duas considerações iniciais devem ser feitas quanto aos recursos voltados para a participação encontrados nestes websites. Primeiramente, pode-se notar que os sites legislativos aqui estudados ainda apelam, em sua maioria, para uma modalidade offline de contato com os cidadãos. Ou seja, conforme observado, boa parte dos mecanismos ofertados que implicam algum tipo de interação entre cidadãos e Poder Legislativo se limita em disponibilizar números de telefones e endereços físicos. Há, também, uma grande quantidade de endereços de e-mail nestes websites, o que representa um avanço tímido naquilo que concerne a uma aproximação entre esfera civil e esfera política.

O site da Assembléia Legislativa do Estado da Bahia, por exemplo, não provê mecanismos de participação online, privilegiando uma lógica ainda tradicional de comunicação entre cidadão e poder público. Setores do Poder Legislativo baiano, como a Ouvidoria, dão preferência ao contato por telefone e por carta.

\footnotetext{
9 Disponível em: <http://www.al.ba.gov.br/>. Acesso em 14/05/2007.

${ }^{10}$ Disponível em: <http://www.assembleia.go.gov.br/>. Acesso em 14/05/2007.

${ }_{11}$ Disponível em: <http://www.alepa.pa.gov.br/>. Acesso em 14/05/2007.

${ }_{12}$ Disponível em: $<$ http://www.al.rs.gov.br/>. Acesso em 14/05/2007.

13 Disponível em: <http://www.al.sp.gov.br/portal/site/alesp/>. Acesso em 14/05/2007.
} 
Em segundo lugar, deve-se considerar a natureza diferenciada de alguns recursos disponíveis. Isto é, de acordo com o perfil ideal das práticas democráticas traçado no tópico anterior deste trabalho, há, por um lado, ferramentas de participação online que obedecem a uma lógica individualista e, por outro, dispositivos mais adequados a uma interferência civil na qual os interessados podem tomar parte no processo de discussão dos negócios públicos.

O oferecimento de e-mail para contato na maioria das experiências é farto, mas é de se duvidar das capacidades deliberativas desta ferramenta, isto porque tal recurso obedece, geralmente, a um modelo privado de comunicação, não fornecendo garantias de que os argumentos em questão contenham razões públicas que sejam mutuamente aceitáveis. Este aspecto põe em xeque o senso de responsabilidade que o engajamento em uma esfera discursiva requer. Boa parte dos websites aqui exemplificados, assim, parece aderir mais a uma lógica do cliente (ou seja, aquela na qual o cidadão procura uma informação primordialmente para preencher necessidades privadas) do que a uma lógica do cidadão atuando deliberativamente.

O site da Assembléia Legislativa do Rio Grande do Sul é um dos mais sofisticados no que concerne ao oferecimento de contatos através de e-mail. Nele, estão disponíveis formulários e endereços eletrônicos específicos para lidar com diferentes partes da estrutura organizacional, a exemplo da ouvidoria e de funcionários do corpo técnico da instituição. O site da Assembléia gaúcha, adicionalmente, dá aos cidadãos a possibilidade de entrarem em contato com aqueles que elaboram as informações que constam no site daquela instituição legislativa.

O site da Assembléia paulista chama a atenção, assim como o site gaúcho, pela variedade de formas de contato que oferece com os diferentes setores da casa. Não apenas os deputados, mas os líderes de bancada e de partido têm seus telefones e endereços de e-mail publicados (o que também ocorre no site da Câmara dos Deputados).

O website da Câmara dos Deputados, além de contar com uma organização que facilita a navegação entre as páginas, prima pela riqueza de formas de contato gerais e setorizadas. Os formulários eletrônicos (que, mesmo constituindo uma ferramenta diferente do e-mail, obedecem a uma lógica semelhante de contato) estão 
dispostos de modo a satisfazer diferentes finalidades (elogiar, sugerir, solicitar, reclamar, denunciar) e a atingir diferentes destinatários. Pode-se especificar, por exemplo, o encaminhamento da mensagem para a instituição ou para os deputados, com a possibilidade de se comunicar com os parlamentares individualmente ou com vários destinatários selecionados por partidos, estados ou, mesmo, com todos os legisladores.

Alguns outros websites, como o de Goiás, mal oferecem o e-mail como forma de contato. Além de não especificar os endereços eletrônicos de comissões e de departamentos da Assembléia, o site goiano torna disponíveis os endereços digitais dos deputados sem se preocupar em fornecer um contato online geral para que o cidadão se reporte à Assembléia enquanto instituição (apenas o e-mail do webmaster está disponível).

Tal disposição dos websites favorece uma interação individual por parte dos integrantes da esfera civil e suscita questionamentos relativos ao papel que as casas legislativas e seus parlamentares atribuem aos cidadãos na divisão do trabalho político. Ou seja, os cidadãos não parecem ser vistos em conjunto, atuando como parceiros na elaboração das normas.

Não é que se afirme que, ao privilegiarem ferramentas de participação e interação individual, os sites em questão não permitam que os cidadãos, ainda que privadamente, enviem contribuições e sugestões sobre políticas e projetos em discussão. O que se defende, fundamentado em uma perspectiva deliberativa de democracia, é a existência de mecanismos que permitam que a esfera civil interaja coletivamente nas discussões de natureza pública. James Bohman reafirma este aspecto ao defender que os cidadãos, reunidos em público, sejam vistos como fontes de informação e julgamento das propostas em tramitação:

Such institutions developed specialized competence and employ expert knowledge; however, they regard the citizens they interact with as objects of control and manipulation. In democratically structured administration, citizens should be regarded not as passive clients but as sources of information and judgments, especially concerning the contextual features of applying laws and agreements to specific local situations" (BOHMAN, 1996, p. 189).

Pode-se concluir, a partir da exploração empreendida, que os recursos identificados cuja natureza demanda uma participação coletiva e discursiva dos 
cidadãos através da Internet são inexistentes, à exceção do site da Câmara. Ao privilegiar ferramentas de participação de perspectiva individualista, este sites pouco colaboram para uma troca pública de argumentos, conforme requer o modelo deliberacionista de democracia.

Um dos destaques do site da Câmara dos Deputados é a seção de participação popular, que contém uma ferramenta denominada "Sua proposta pode virar lei”, gerenciada pela Comissão de Legislação Participativa. Este recurso informa aos cidadãos como enviar sugestões de proposições legislativas de acordo com os dispositivos regimentais e oferece arquivos contendo modelos para a elaboração de propostas.

Uma vez elaboradas as proposições, os agentes que preenchem os requisitos mínimos, conforme estabelecido pelas regras da Câmara, podem enviar os arquivos com suas demandas através do próprio site ${ }^{14}$. No entanto, o conteúdo propostas apresentadas não está disponível ao público e nem o site da Câmara dispõe de um sistema que permita acompanhar o andamento dos processos. Portanto, embora a ferramenta de envio de propostas pressuponha uma participação coletiva, a possibilidade do estabelecimento do debate público é excluída, pois grupos que compartilhem ou discordem do teor das proposições têm sua oportunidade de contribuir no aperfeiçoamento das razões interditada.

Ainda que este trabalho não investigue os diferentes artifícios que podem ser empregados para estimular os cidadãos a participarem do jogo político, é necessário tornar evidente que as contribuições endereçadas serão efetivamente consideradas e receberão a atenção devida por parte do Poder Público. Nestes termos, o desenvolvimento de um sistema de monitoramento de demandas, por exemplo, possui função importante no processo de convencimento da esfera civil a tomar parte na elaboração das políticas públicas.

A Câmara dos Deputados promove bate-papos que contam com a presença de parlamentares - normalmente o relator do projeto pertinente a um assunto específico. As conversas são agendadas com antecedência e divulgadas no site da

\footnotetext{
14 De acordo com instruções da Comissão de Legislação Participativa, para se lançar mão deste recurso exige-se que a apresentação das propostas seja intermediada por grupos como ONGs, associações, órgãos de classe e entidades da sociedade civil organizada.
} 
Agência Câmara, por onde também se dá o acesso à sala de bate-papo. O site da Câmara destaca o link para o acesso dos chats realizados anteriormente e os classifica por data, informando os temas debatidos em cada um e o parlamentar que deles tomaram parte. As perguntas e respostas das conversações arquivadas são agrupadas por assuntos.

Os temas abordados nos chats constituem pauta do Congresso, já que a origem do debate reside, normalmente, nas proposições em tramitação na casa (como, por exemplo, a redução da maioridade penal, planejamento familiar e assistência social, políticas ambientais, dentre outras). Ressalte-se que os temas discutidos nestas conversações requerem inputs de razões públicas por parte dos cidadãos. A oportunidade de participação em debates com representantes políticos significa, assim, uma forma de aproximação entre legislativo e esfera civil.

A Câmara dos Deputados conta, também, com fóruns de debate temáticos que permitem aos usuários o envio de comentários e o acompanhamento das discussões através de e-mail. Para participar dos fóruns, é necessário cadastro prévio e autenticação no website. Os fóruns disponíveis no site da Câmara têm temáticas limitadas e atualização deficiente. No período visitado para efeitos de investigação, apenas um tema ("Qual a sua sugestão para o anteprojeto de substitutivo apresentado ao Projeto de Lei $n^{0}$ 1.528, que trata da Organização Sindical?”) estava aberto ao debate e um outro ("Como a Câmara dos Deputados pode aproximar você, cidadão, e a sociedade civil organizada da Comissão de Legislação Participativa?”) já havia encerrado as contribuições.

Conforme defendem autores do modelo discursivo (Bohman, 1996; Gastil, 2000; Gutmann e Thompson, 1996), a conjunção dos argumentos de parlamentares e cidadãos, possibilitada a partir do emprego de mecanismos tais como os chats e os fóruns públicos, respeita o princípio de accountability, essencial à própria natureza do sistema representativo, de acordo com o deliberacionismo. Nestas ocasiões, os parlamentares encontram formas adicionais de oferecer justificativas às suas decisões políticas e, dada a possibilidade de interação, os cidadãos têm como perquirir seus representantes e contribuir com o aperfeiçoamento das políticas públicas. 
Deve-se ressaltar que três websites, a saber, os das Assembléias Legislativas da Bahia, de Goiás e do Pará, têm desempenhos nitidamente inferiores uma vez comparados aos dos estados de São Paulo e do Rio Grande do Sul e da Câmara dos Deputados. O website da Assembléia Legislativa do estado de Goiás apresenta deficiências inclusive do ponto de vista informativo. Não há, sequer, biografia resumida dos deputados ou a descrição mínima das atividades e atribuições das comissões. Além disso, conforme já ressaltado, o endereço de e-mail institucional da casa não está disponível.

Em relação ao site da Assembléia paraense, também não se pode constatar a existência de mecanismos mais aprofundados de participação. A seção "Fale conosco" oferece, apenas em casos esporádicos, o endereço de contato por e-mail.

Já o website da Assembléia da Bahia dispõe de informações mais aprofundadas do que aquelas encontradas no caso de Goiás e Pará. Por outro lado, percebe-se, igualmente aos sites daqueles dois estados, uma insistência nas modalidades offline de comunicação, o que demonstra uma apropriação ineficiente das tecnologias de comunicação digital.

Pelo que se depreende a partir do exame da amostra selecionada, apenas uma experiência, aquela da Câmara dos Deputados, oferece mecanismos que possibilitam uma troca de razões de acordo com o que estabelecem os patamares da deliberação pública. Não é possível fazer maiores inferências acerca da idéia de soberania popular ou da concepção de democracia e participação que estas casas legislativas possuem (tal empreendimento requer um estudo mais ampliado das formatações históricas, cultura política e demais diretrizes que regem as atividades dos diferentes parlamentos). Assim, não se afirma que a participação seja, necessariamente, considerada supérflua nas experiências aqui consideradas. Os elementos examinados por este trabalho, entretanto, apontam indícios de subaproveitamento dos artifícios técnicos oferecidos pelos new media. Isso prova que não basta a viabilidade e a disponibilidade das ferramentas para que os recursos sejam aplicados de maneira a atender determinados princípios sugeridos por modelos de democracia a exemplo do deliberacionismo. 
Autores a exemplo de Stephen Coleman ressaltam que, mesmo tendo à disposição um conjunto de recursos apto a inaugurar novas formas de relacionamento entre, por exemplo, esfera civil e esfera dos representantes políticos, nem sempre as instituições do estado lançam mão de tais artifícios de forma a contemplar uma perspectiva forte de soberania popular. Para Coleman: "In particular, there is a concern about the sub-optimal design and development of websites that lead to their democratic usefulness being to support political elites at the expense of the wider citizenry" (COLEMAN et al., 1999, p. 8).

Este uso precário dos recursos disponíveis gera frustrações naqueles que, desde os primórdios do desenvolvimento da Internet, vêm confiando às redes digitais a criação de maiores oportunidades de exercício da influência política por parte dos cidadãos. Estas frustrações estão relacionadas à constatação de que as sociedades democráticas contemporâneas enfrentam dificuldades no que concerne à realização de ideais políticos firmados, sobretudo, a partir do século XVIII. Põe-se luz, como faz Norberto Bobbio (2004), no fato de que a democracia não cumpriu várias daquelas promessas como extinguir o "poder invisível” das burocracias. É exatamente como uma tentativa de se amenizar alguns destes problemas que a Internet tem sido apontada como elemento a revigorar certos ideais democráticos (AINSWORTH et al., 2005; CARPINI, 2000). Entretanto, pelo que se demonstra a partir deste trabalho, mesmo que as soluções oferecidas pelas novas tecnologias de comunicação conformem um aspecto importante para aproximar cidadãos e instituições democráticas, a adoção destes recursos acaba sendo, na verdade, resultado de uma disposição política prévia. Em outras palavras, não se deve perder de vista que o emprego destas ferramentas em maior ou menor medida está refletido na interface entre a comunicação e a política.

\section{Conclusão}

A proposta deste trabalho se referiu à identificação e à avaliação de recursos digitais de participação presentes em websites de instituições do Poder Legislativo. O recorte escolhido para este trabalho se referiu às diferentes modalidades de intervenção dos cidadãos encontradas no site da Câmara dos Deputados e nos sites 
das Assembléias Legislativas dos estados da Bahia, Goiás, Pará, Rio Grande do Sul e São Paulo.

O emprego mais ou menos tímido de oportunidades de participação mediante o acesso a estes websites pode ser medido pela quantidade e pela qualidade de ferramentas de intervenção civil oferecidas. Para definir que tipo de recurso pode ser considerado apto a preencher os requisitos de uma participação democrática efetiva, procurou-se fundamentar a avaliação e a idealização de ferramentas digitais a partir dos princípios estabelecidos pelo modelo deliberativo.

O deliberacionismo tem como uma de suas metas a interferência mais ousada da esfera civil quando da produção da decisão política. Os autores da vertente deliberativa consideram que uma intervenção mais forte dos cidadãos é necessária tanto por conferir maior legitimidade ao regime democrático de governo, quanto por adicionar novas perspectivas à formulação e justificação de políticas públicas. Não se pense, todavia, que os deliberacionistas defendem qualquer tipo de participação. $\mathrm{Na}$ visão de Bohman (1996) e Gutmann e Thompson (1996), os cidadãos, quando do processo de interação discursiva, estão sujeitos a determinados tipos de regulação, cuja atuação se dá, primordialmente, no comportamento dos agentes em disputa argumentativa e na essência dos conteúdos das razões erigidas em público.

Neste contexto, os recursos da Internet são vistos como aptos a fomentar mecanismos deliberativos de participação. Mas até que ponto este potencial das redes digitais é empregado de maneira satisfatória? O estudo dos seis websites legislativos neste trabalho permite concluir que as possibilidades oferecidas pela Internet vêm sendo aproveitadas de modo insuficiente ${ }^{15}$. A ferramenta mais recorrente a implicar algum tipo de interação se refere ao oferecimento de endereços de e-mail para que os usuários entrem em contato. $\mathrm{O}$ único site a oferecer formas mais consistentes de participação deliberativa, implicando troca pública de razões, foi o da Câmara dos Deputados, através da realização de chats e de fóruns para discussão de proposições legislativas em andamento.

\footnotetext{
15 Neste momento, o que as análises empíricas existentes acerca da qualidade dos websites de instituições democráticas permitem afirmar é que estas inciativas se concentram, fundamentalmente, na prestação de informações aos cidadãos, conforme conclusão de Sivado Pereira da Silva (2005).
} 
Assim, o que se pode notar em vários sites de instituições políticas centrais na conformação de sociedades democráticas é uma mera presença na rede, com uma iniciativa dedicada, basicamente, a prover informações em formato unidirecional e sem se preocupar em absorver as contribuições e disposições dos cidadãos. O diagnóstico desse trabalho dá conta de que as ferramentas digitais são subaproveitadas no que se refere ao aperfeiçoamento da participação da esfera civil na produção da decisão política.

Se a intenção é diminuir o gap entre o trabalho político da esfera dos representantes e o da esfera civil, deve-se sugerir às instituições legislativas e aos parlamentares o emprego efetivo e a ampliação de mecanismos que valorizem a participação dos cidadãos e que levem em conta o julgamento público das razões em jogo. Neste sentido, uma maior porosidade do Poder Legislativo extrapola a competência dos instrumentos de comunicação disponíveis e se volta para a disposição da esfera política em se mostrar cada vez mais transparente ou em ouvir as sugestões dos cidadãos.

\section{Referências}

AINSWORTH, S., HARDY, S. and HARLEY, B. (2005). "Online Consultation: EDemocracy and E-Resistance in the Case of the Development Gateway". In: Management Communication Quarterly, Vol. 19, No. 1, 120-145.

BOBBIO, N. (2004). O futuro da democracia. Trad. Marco Aurélio Nogueira. $9^{\mathrm{a}}$ ed. Rio de Janeiro: Paz e Terra.

BOHMAN, J. (1996). Public Deliberation: Pluralism, Complexity and Democracy. Cambridge, MIT Press.

CARPINI, M. X. D. (2000). "Gen.com: Youth, Civic Engagement, and the New Information Environment”. In: Political Communication 17: 341-349.

COLEMAN, S., TAYLOR, J. and VAN DE DONK, W. (eds.) (1999) Parliament in the Age of the Internet, OUP, Oxford, 3-8.

DOWNS, A. (1999). Uma teoria econômica da democracia. Tradução de Sandra Guardini Teixeira Vasconcelos. São Paulo: Editora da Universidade de São Paulo. 
DRYZEK, J. S. (2004). "Legitimidade e economia na democracia deliberativa”. In: COELHO, Vera S. P.; NOBRE, Marcos. Participação e deliberação - teoria democrática e experiências institucionais no Brasil contemporâneo. São Paulo: Editora 34, p. 41-62.

FISHKIN, J. S. (1991). Democracy and Deliberation: New Directions in Democratic Reform. New Haven, CT: Yale University Press.

GASTIL, J. (2000). By Popular Demand: Revitalizing Representative Democracy Through Deliberative Elections. Berkeley, CA: University of California Press.

GOMES, W. S. (2005). A democracia digital e o problema da participação civil na decisão política.. Revista Fronteiras, São Leopoldo, v. VIII, n. 3, p. 214-222, 2005 .

GUTMANN, A. and THOMPSON, D. (1996). Democracy and Disagreement. Cambridge, MA: Harvard University Press.

MARQUES, F. P. J. A. (2004). Dimensões da Ciberdemocracia: conceitos e experiências fundamentais, 2004. Dissertação (Mestrado). Programa de Pós Graduação em Comunicação e Culturas Contemporâneas. Salvador.

NEGROPONTE, N. (1995). A vida digital. São Paulo: Companhia da Letras.

OECD. (2003). Promise and Problems of E-Democracy: Challenges of Citizen On-line Engagement. Paris: OECD.

ROUSSEAU, J.J. (2002). O Contrato Social e outros escritos. 14 ed., S. Paulo: Cultrix.

SCHUMPETER, J. A. (1942). Capitalism, Socialism, and Democracy. New York: Harper and Brothers.

SILVA, S. P. (2005). Graus de participação democrática no uso da internet pelos governos das capitais brasileiras. Opinião Pública, Oct., vol.11, n.2, p.450-468. 